Check for updates

Cite this: RSC Adv., 2017, 7, 24643

Received 17th February 2017

Accepted 30th April 2017

DOI: 10.1039/c7ra01983a

rsc.li/rsc-advances

\section{Copper(II)-mediated formation of oxazole-4- carbonitrile from acetophenone and coordinated cyanide anion via a radical coupling $\dagger$}

\author{
Congjun Xu,ł Mingze Qin, \$ Jun Yi, Yanjing Wang, Yanfeng Chen, Bingfu Zhang, \\ Yanfang Zhao* and Ping Gong (D)*
}

A protocol for the direct synthesis of 5-aryloxazole-4-carbonitrile from acetophenone was first described with potassium ferricyanide as a cheap and low toxicity cyanide reagent, in which, multiple bond formation was implemented via an oxygen mediated radical mechanism. Potassium ferricyanide played a dual role as a "CN" source and also as a coupling partner for the cyclization of oxazole.
Oxazole derivatives, one of the most important heterocyclic compounds, are widely present in natural products, ${ }^{1}$ synthesized drugs ${ }^{2}$ and advanced materials. ${ }^{3}$ Meanwhile, a significant proportion of drugs used in clinical treatment contain a cyano group. ${ }^{4}$ In addition, the introduction of a cyano group to smallmolecule lead compounds is one of the most critical strategies in drug development because the cyano group can be easily converted into amide, carboxylic acid, imido ester, amidine, and methyl ammonia groups. ${ }^{5,6}$ Thus, the introduction of a cyano group to an oxazole ring is an appealing idea.

Over the years, many strategies for the preparation of cyanooxazoles have been developed, which includes the dehydration of carboxamides to nitriles, ${ }^{7-9}$ nucleophilic substitution on oxazoles $^{10}$ and intramolecular condensation of $\beta$-acyloxyenamines (Scheme 1). ${ }^{11}$ These methods suffered from harsh reaction conditions, toxic reagents or unavailable starting materials. Herein, exploring the potential of non-toxic and efficient systems is imperative, which might provide a smooth approach to construct carbonitrile from ubiquitously present substrates.

Initially, the authors tried to develop an efficient cyano substitution reaction via $\mathrm{C}-\mathrm{H}$ bond activation ${ }^{12}$ with acetophenone as the substrate using nontoxic cyanide sources, such as potassium ferricyanide and potassium ferrocyanide (Scheme 2). Quite incidentally, 5-phenyloxazole-4-carbonitrile was obtained dramatically in the presence of $\mathrm{CuI}_{2}$ and $\mathrm{Pd}(\mathrm{OAc})_{2}$ with DMF as solvent (Scheme 2). The surprising results aroused our interesting and the reaction was investigated further. Subsequently,

Key Laboratory of Structure-based Drug Design and Discovery, Shenyang Pharmaceutical University, Ministry of Education, 103 Wenhua Road, Shenhe District, Shenyang 110016, People's Republic of China. E-mail: yanfangzhao@126. com; gongpinggp@126.com

$\dagger$ Electronic supplementary information (ESI) available. See DOI: 10.1039/c7ra01983a

$\ddagger$ These authors contributed equally to this work. we found that 5-phenyloxazole-4-carbonitrile was obtained smoothly in the absence of $\operatorname{Pd}(\mathrm{AcO})_{2}$.

To gain a better understanding of this attractive result, we systematically studied the function of oxidants and cyanide (Table 1). At the beginning of the investigation, the reaction of acetophenone (1a), DMF, and potassium ferricyanide was examined in the presence of $\mathrm{CuI}_{2}\left(1.0\right.$ equiv.) at $130^{\circ} \mathrm{C}$ for $12 \mathrm{~h}$. The expected 5-phenyloxazole-4-carbonitrile (2a) was obtained in $29 \%$ yield with the formation of side product $N, N$-dimethyl-2oxo-2-phenylacetamide ${ }^{13}$ in $19 \%$ yield, and $40 \%$ of raw material was recovered (Table 1, entry 1). The reaction did not occur in the absence of $\mathrm{CuI}_{2}$ or $\mathrm{K}_{3}\left[\mathrm{Fe}(\mathrm{CN})_{6}\right]$ (entries 2 and 3). The other oxidants such as $\mathrm{CuI}, \mathrm{FeBr}_{3}$ and $\mathrm{ZnBr}_{2}$ were investigated (entries 4-10). The yield of 2 a was up to $75 \%$ when $\mathrm{CuBr}_{2}$ was used as the oxidant (entry 10). It was found out that the effects of $\mathrm{Cu}$ (II) salts and $\mathrm{Fe}(\mathrm{III})$ salts was superior to $\mathrm{Cu}(\mathrm{I})$ salts in the system. Organic oxidants, such as NBS, were tested to enhance the conversion of this reaction. However, only inferior conversion was observed (entries 12). The use of KCN, CuCN or $\mathrm{K}_{4}\left[\mathrm{Fe}(\mathrm{CN})_{6}\right]$ instead of $\mathrm{K}_{3}\left[\mathrm{Fe}(\mathrm{CN})_{6}\right]$ also led to the formation (entry 15-17), but only

a) Cyanation of oxazole precursors

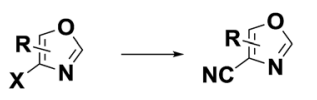

$\mathrm{X}=\mathrm{CONH}_{2}, \mathrm{CHO}, \mathrm{CH}_{2} \mathrm{OH}, \mathrm{Br}, \mathrm{I}$

b) Cycization of the substrate containing ready-made "CN"
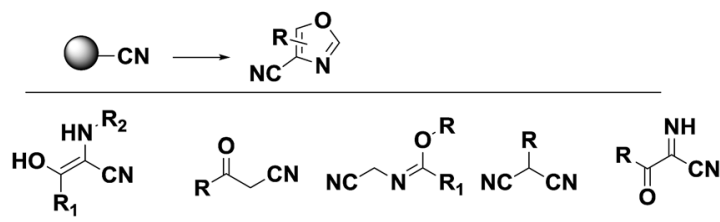

Scheme 1 Synthesis of oxazole-4-carbonitrile. 


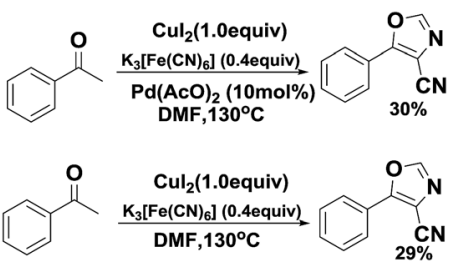

Scheme 2 A surprising result.

Table 1 Optimization of the reaction conditions ${ }^{a}$

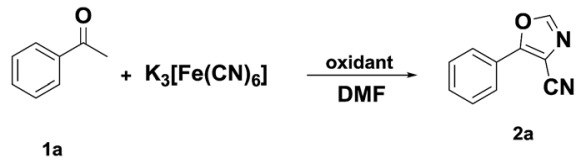

\begin{tabular}{llll}
\hline Entry & Oxidant & Cyanide & Yield $^{b}(\%)$ \\
\hline 1 & $\mathrm{CuI}_{2}$ & $\mathrm{~K}_{3} \mathrm{Fe}(\mathrm{CN})_{6}$ & 29 \\
2 & - & $\mathrm{K}_{3} \mathrm{Fe}(\mathrm{CN})_{6}$ & $\mathrm{NR}$ \\
3 & $\mathrm{CuI}_{2}$ & - & $\mathrm{NR}$ \\
4 & $\mathrm{CuCl}$ & $\mathrm{K}_{3} \mathrm{Fe}(\mathrm{CN})_{6}$ & $\mathrm{NR}$ \\
5 & $\mathrm{CuI}$ & $\mathrm{K}_{3} \mathrm{Fe}(\mathrm{CN})_{6}$ & Trace \\
6 & $\mathrm{FeBr}_{3}$ & $\mathrm{~K}_{3} \mathrm{Fe}(\mathrm{CN})_{6}$ & 40 \\
7 & $\mathrm{ZnBr}_{2}$ & $\mathrm{~K}_{3} \mathrm{Fe}(\mathrm{CN})_{6}$ & $\mathrm{NR}$ \\
8 & $\mathrm{CuCl}_{2}$ & $\mathrm{~K}_{3} \mathrm{Fe}(\mathrm{CN})_{6}$ & 50 \\
9 & $\mathrm{CuBr}_{13}$ & $\mathrm{~K}_{3} \mathrm{Fe}(\mathrm{CN})_{6}$ & $\mathrm{NR}$ \\
10 & $\mathrm{CuBr}_{2}$ & $\mathrm{~K}_{3} \mathrm{Fe}(\mathrm{CN})_{6}$ & 75 \\
11 & ${\mathrm{CuO} / \mathrm{I}_{2}}_{12}$ & $\mathrm{~K}_{3} \mathrm{Fe}(\mathrm{CN})_{6}$ & 26 \\
15 & $\mathrm{NBS}_{16}$ & $\mathrm{~K}_{3} \mathrm{Fe}(\mathrm{CN})_{6}$ & Trace \\
17 & $\mathrm{CuBr}_{2}$ & $\mathrm{CuCN}$ & 39 \\
$18^{c}$ & $\mathrm{CuBr}_{2}$ & $\mathrm{KCN}$ & 70 \\
$19^{d}$ & $\mathrm{CuBr}_{2}$ & $\mathrm{~K}_{4} \mathrm{Fe}(\mathrm{CN})_{6}$ & 43 \\
& $\mathrm{CuBr}_{2}$ & $\mathrm{~K}_{3} \mathrm{Fe}(\mathrm{CN})_{6}$ & $\mathrm{NR}$ \\
\hline $\mathrm{CuBr}_{2}$ & $\mathrm{~K}_{3} \mathrm{Fe}(\mathrm{CN})_{6}$ & 71
\end{tabular}

${ }^{a}$ Reaction conditions: 1a $(1.0 \mathrm{mmol}), \mathrm{K}_{3}\left[\mathrm{Fe}(\mathrm{CN})_{6}\right](0.4 \mathrm{mmol})$ or $\mathrm{KCN}$ $(2.0 \mathrm{mmol})$ or CuCN $(2.0 \mathrm{mmol})$, DMF $(3 \mathrm{~mL})$, oxidant $(1.0 \mathrm{mmol})$, at $130{ }^{\circ} \mathrm{C}$. ${ }^{b}$ Isolated yield. ${ }^{c}$ Nitrogen atmosphere. NR: no desired product was detected. ${ }^{d}$ Oxygen balloon.

using KCN showed good result (entry 16). From the safety and yield point of view, $\mathrm{K}_{3}\left[\mathrm{Fe}(\mathrm{CN})_{6}\right]$ was chosen as the cyanide source. Interestingly, in an exclusive nitrogen atmosphere, the transformation was shut down (entry 18), which indicated that $\mathrm{O}_{2}$ play a crucial role in the reaction. In addition, when the reaction was performed under an $\mathrm{O}_{2}$ atmosphere, the result was the same as that under an air atmosphere (entry 19).

Next, we turned our attention to the effect of solvent on the reaction. It turned out that 5-phenyloxazole-4-carbonitrile was not detected when DMF was replaced with other solvents, such as acetonitrile, dimethyl sulfoxide, $N$-methyl-2-pyrrolidone or ethylene glycol, which indicated that the DMF is indispensable in the reaction. Considering that DMF has the capability to participate in the reaction, ${ }^{\mathbf{1 4}}$ a control experiment with DMF-d7 as the solvent was carried out (Scheme 3). 5-Phenyloxazole-4carbonitrile-2-d was not detected, which means that DMF participate in this reaction only as an excellent solvent involving coordinated cyanide anion. ${ }^{\mathbf{1 2 a}, 15}$ Meanwhile, it turned out that

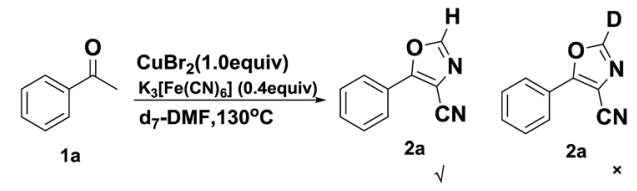

Scheme 3 Control experiments for investigating the role of DMF.

the " $\mathrm{CN}$ " in $\mathrm{K}_{3}\left[\mathrm{Fe}(\mathrm{CN})_{6}\right]$ also participated in the cyclization rather than DMF.

With the optimized conditions in hand (Table 1, entry 10), the scope of substrates for the reaction was explored. The structures and yields of the products are summarized in Scheme 4.

Almost all of the starting acetophenones bearing monosubstitution or poly-substitution were successfully transformed into the desired 4-carbonitrile products in moderate to good yields. In addition, the electronic properties of the substituents on the aromatic ring significantly influenced the efficiency of this transformation. The reactions of 4-fluoro, 4-bromo, and 3-chloro acetophenone proceeded smoothly to afford the corresponding products (2f-2h) in excellent yields. Furthermore, the optimized reaction conditions were also applicable to acetophenones with the electron-donating substituents (2b-2d). However, the strong electron-withdrawing groups on acetophenone, such as $-\mathrm{NO}_{2}$, hindered the conversion $(2 \mathbf{i}$ and $2 \mathbf{j}$ ) and the reaction required a high temperature. A low yield was observed in the case of 2substituted acetophenones $(\mathbf{2} \mathbf{j}-\mathbf{2 l})$ due to the influence of steric hindrance. Besides, the reactions of methyl 4-acetylbenzoate proceeded smoothly to afford the corresponding products (2e), while, the starting acetophenones bearing aldehydes ${ }^{18 a}$ or acids were hardly transformed into the desired 4-carbonitrile products.

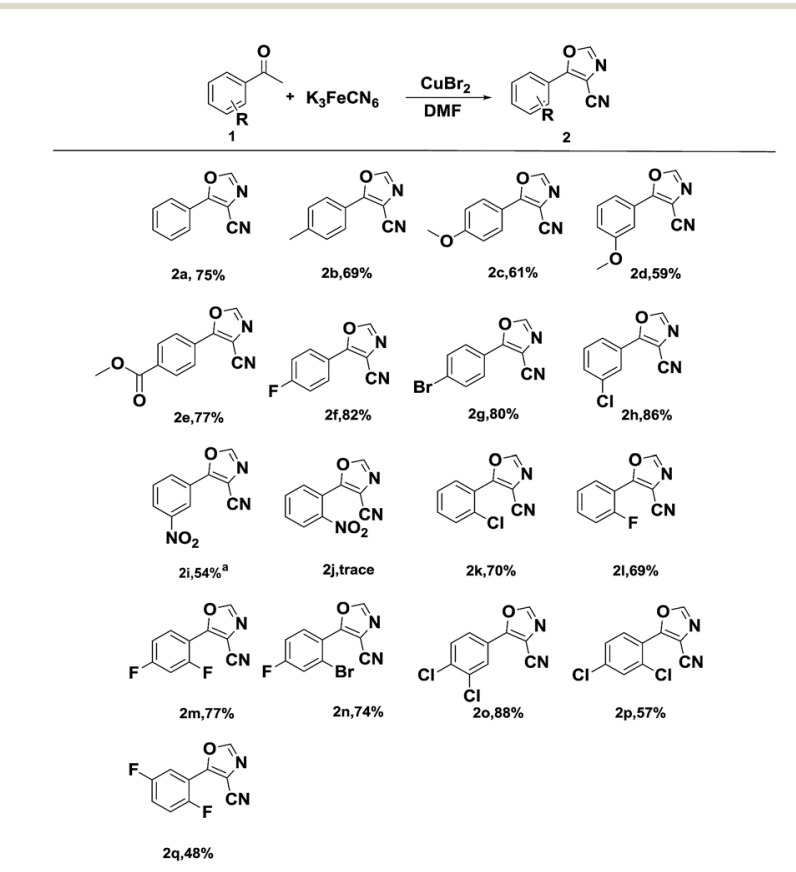

Scheme 4 Scope of acetophenones. Reaction conditions: 1a (1.0 $\mathrm{mmol}), \mathrm{K}_{3}\left[\mathrm{Fe}(\mathrm{CN})_{6}\right](0.4 \mathrm{mmol}), \operatorname{DMF}(3 \mathrm{~mL}), \mathrm{CuBr}_{2}(1.0 \mathrm{mmol})$, at $130{ }^{\circ} \mathrm{C}$. Isolated yield. ${ }^{\mathrm{a}} \mathrm{At} 140^{\circ} \mathrm{C}$. 
Subsequently, in order to gain insight into the reaction mechanism, several control experiments were performed as shown in Scheme 5. We proposed a plausible reaction pathway involving the formation of an intermediate, such as 2-bromo-1phenylethan-1-one (3ab) and 3-oxo-3-phenylpropanenitrile (3ac) via halogenation ${ }^{\mathbf{1 6}}$ and nucleophilic reaction. ${ }^{\mathbf{1 7}}$ In subsequent experiments, both 3ab and 3ac transformed to the desired 2a in a comparative yields, which implied that the transfer undergo the halogenation and nucleophilic process. Furthermore, ethyl benzoylacetate could converse to the desired ethyl 5phenyloxazole-4-carboxylate in this system (2ac).

In addition, it is noteworthy that the reaction was inhibited in the presence of radical scavengers, suggesting the possibility of a radical pathway (Scheme 6).

On the base of experimental results and according to previous studies, ${ }^{\mathbf{1 6 - 2 0}}$ a possible reaction mechanism is proposed and shown in Scheme 7. Firstly, acetophenone transferred to 3-oxo-3-phenylpropanenitrile (3ac) via halogenation $^{\mathbf{1 4}}$ and nucleophilic ${ }^{\mathbf{1 5}}$ reaction in the presence of $\mathrm{CuBr}_{2}$ and $\mathrm{K}_{3}\left[\mathrm{Fe}(\mathrm{CN})_{6}\right]$. Next, $\mathrm{Cu}^{\mathrm{II}}$ served as a single electron oxidant to convert the 3ac to the radical species $4 .^{18}$ The $\mathrm{Cu}^{\mathrm{I}} \mathrm{CN}^{18 a}$ species then combines with radical species 4 to generate the $\mathrm{Cu}^{\mathrm{I}}$ bonded radical intermediate $\mathbf{5}$. Immediately, intermediate $\mathbf{5}$ transformed to the radical intermediate $\mathbf{6}$ via cyclization, ${ }^{19}$ which was oxidized by CuII to form the cationic intermediate 7. ${ }^{20}$ Finally, the desired product $2 \mathrm{a}$ is obtained from 7 via elimination reaction.

In conclusion, an efficient, low-toxicity formation of 5aryloxazole-4-carbonitrile from acetophenone was developed using potassium ferricyanide as a cyanide reagent with $\mathrm{Cu}$ (II) bromide as an oxidan, in which, potassium ferricyanide played a dual role as a "CN" source and also as a coupling partner for the cyclization of oxazole. The reaction conditions are mild and suitable for a wide range of substrates. Most of these substrates, such as 4-fluoro, 3-chloro, and 4-bromo acetophenone, provide

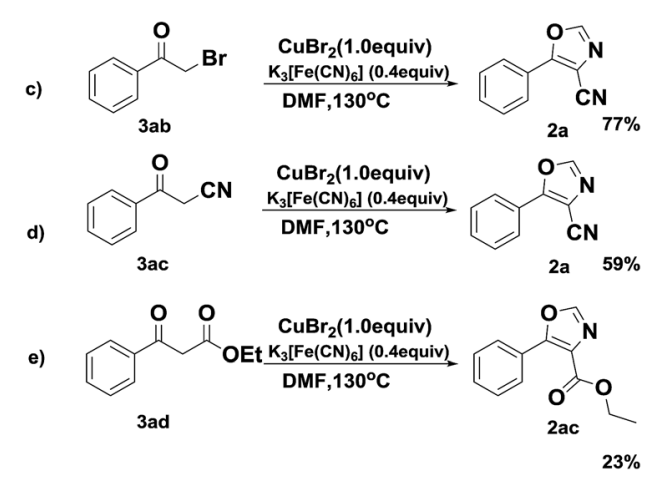

Scheme 5 Control experiments for investigating the possible intermediates for the reaction.

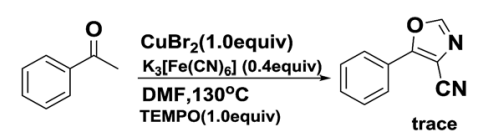

Scheme 6 Control experiments for investigating the reaction type.

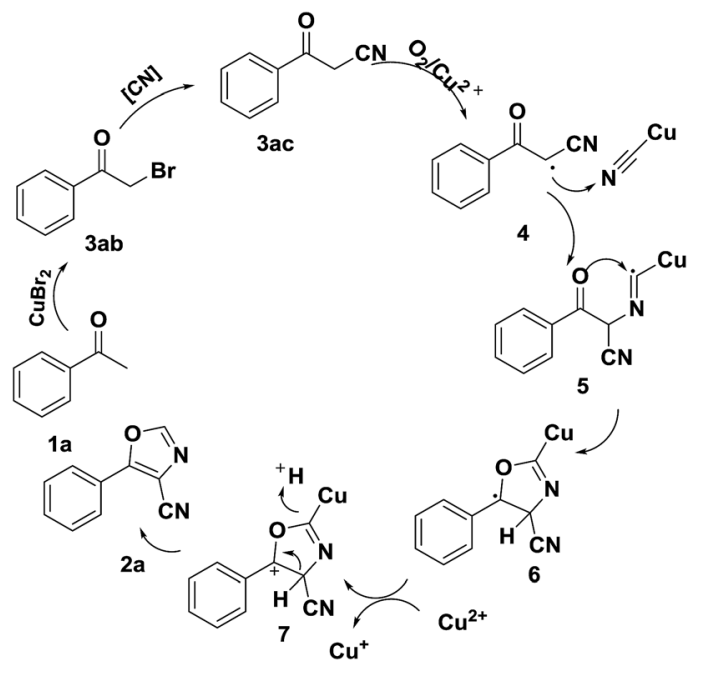

Scheme 7 Proposed mechanism.

the corresponding products in moderate to excellent yields. In addition, the dramatic multiple bond formation provides a practical one-pot access to various 5-aryloxazole-4-carbonitrile derivatives from accessible raw materials. In addition, a reasonable reaction mechanism was proposed.

\section{Notes and references}

1 (a) W. Wang, D. Yao, M. Gu, M. Fan, J. Li, Y. Xing and F. Nan, Bioorg. Med. Chem. Lett., 2005, 15, 5284; (b) N. Desroy, F. Moreau, S. Briet, G. Le Fralliec, S. Floquet, L. Durant, V. Vongsouthi, V. Gerusz, A. Denis and S. Escaich, Bioorg. Med. Chem., 2009, 17, 1276; (c) S. Heng, K. R. Gryncel and E. R. Kantrowitz, Bioorg. Med. Chem., 2009, 17, 3916; (d) D. S. Dalisay, E. W. Rogers, A. S. Edison and T. F. Molinski, Nat. Prod., 2009, 72, 732; (e) Z. Jin, Nat. Prod. Rep., 2009, 26, 382; (f) Z. Jin, Nat. Prod. Rep., 2011, 28, 1143.

2 (a) S. Heng, K. R. Gryncel and E. R. Kantrowitz, Bioorg. Med. Chem., 2009, 17, 3916; (b) D. S. Dalisay, E. W. Rogers, A. S. Edison and T. F. Molinski, Nat. Prod., 2009, 72, 732; (c) N. Desroy, F. Moreau, S. Briet, G. Le-Fralliec, S. Floquet, L. Durant, V. Vongsouthi, V. Gerusz, A. Denis and S. Escaich, Bioorg. Med. Chem., 2009, 17, 1276; (d) S. Heng, K. R. Gryncel and E. R. Kantrowitz, Bioorg. Med. Chem., 2009, 17, 3916.

3 (a) A. Reiser, L. J. Leyshon, D. Saunders, M. V. Mijovic, A. Bright and J. Bogie, J. Am. Chem. Soc., 1972, 94, 2014; (b) T. Toyo'oka, H. P. Chokshi, R. S. Givens, R. G. Carlson, S. M. Lunte and T. Kuwana, Biomed. Chromatogr., 1993, 7, 208.

4 (a) M. El-Kemary, J. A. Organero, L. Santos and A. J. Douhal, J. Phys. Chem. B, 2006, 110, 14128; (b) C. A. Hughes, L. Robinson, A. Tseng and R. D. MacArthur, Expert Opin. Pharmacother., 2009, 10, 2445; (c) Y. Fradet, Expert Rev. Anticancer Ther., 2004, 4, 37; (d) E. Teodori, S. Dei, A. Garnier-Suillerot, F. Gualtieri, D. Manetti, C. Martelli, 
M. N. Romanelli, S. Scapecchi, P. Sudwan and M. Salerno, J. Med. Chem., 2005, 48, 7426.

5 (a) Y. Ju, F. Liu and C. Li, Org. Lett., 2009, 11, 3582; (b) J. X. Qiao, X. Cheng, D. P. Modi, K. A. Rossi, J. M. Luettgen, R. M. Knabb, P. K. Jadhav and R. R. Wexler, Bioorg. Med. Chem. Lett., 2005, 15, 29; (c) Z. Rappoport, The Chemistry of the Cyano Group, Interscience Publishers: London, 1970.

6 F. F. Fleming, L. H. Yao, P. C. Ravikumar, L. Funk and B. C. Shook, J. Med. Chem., 2010, 53, 7902.

7 (a) W. Bonrath, Ultrason. Sonochem., 2003, 10, 55; (b) B. K. Srivastava, R. Soni, A. Joharapurkar, K. V. Sairam, J. Z. Patel, A. Goswami, S. A. Shedage, S. S. Kara, S. P. Salunke, S. B. Gugale, A. Dhawas, P. Kadam, B. Mishra, N. Sadhwanid, V. B. Unadkatd, P. Mitrad, M. R. Jainb and P. R. Patel, Bioorg. Med. Chem. Lett., 2008, 18, 963.

8 (a) F. A. Romero, I. Hwang and D. L. Boger, J. Am. Chem. Soc., 2006, 128, 14004; (b) F. A. Romero, W. Du, I. Hwang, T. J. Rayl, F. S. Kimball, D. Leung, H. S. Hoover, R. L. Apodaca, J. G. Breitenbucher, B. F. Cravatt and D. L. Boger, J. Med. Chem., 2007, 50, 1058; (c) F. Aquino, R. Karge, H. Pauling and W. Bonrath, Molecules, 1997, 2, 176. 9 (a) J. Linder, T. P. Garner, H. E. Williams, M. S. Searle and C. J. Moody, J. Am. Chem. Soc., 2011, 133, 1044; (b) J. K. DeMartino, J. Garfunkle, D. G. Hochstatter, B. F. Cravatt and D. L. Boger, Bioorg. Med. Chem. Lett., 2008, 18, 5842; (c) H. Wada, H. E. Williams and C. J. Moody, Angew. Chem., Int. Ed., 2015, 54, 15147; (d) V. M. Prokopenko, S. G. Pil'o, A. N. Vasilenko and V. S. Brovarets, Russ. J. Gen. Chem., 2010, 80, 2358.

10 (a) D. Haas, M. Mosrin and P. Knochel, Org. Lett., 2013, 15, 6162; (b) K. Burger, E. Hoss and K. Geith, Synthesis, 1990, 4, 360 .

11 (a) X. Liu, R. Cheng, F. Zhao, D. Zhang-Negrerie, Y. Du and K. Zhao, Org. Lett., 2012, 14, 5282; (b) I. K. Khanna, Y. Yu, R. M. Huff, R. M. Weier, X. Xu, F. J. Koszyk and J. L. Masferrer, J. Med. Chem., 2000, 43, 3168; (c) K. Matsumura, O. Miyashite, H. Shimadzu and N. Hashimoto, Chem. Pharm. Bull., 1976, 24, 948; (d) T. P. Sycheva, T. K. Trupp and M. N. Shchukina, Zh. Obshch. Khim., 1962, 32, 1071; (e) J. W. Cornforth and
H. T. Huang, J. Chem. Soc., 1948, 1969; (f) F. Freeman and D. S. Kim, Tetrahedron Lett., 1989, 30, 2631.

12 (a) X. F. Jia, D. P. Yang, W. H. Wang, F. Luo and J. Cheng, J. Org. Chem., 2009, 74, 9470; (b) G. Yan, C. Kuang, Y. Zhang and J. Wang, Org. Lett., 2010, 12, 1052; (c) Y. Ren, M. Yan, S. Zhao, J. Wang, J. Ma, X. Tian and W. Yin, Adv. Synth. Catal., 2012, 354, 2301.

13 (a) W. P. Mai, H. H. Wang, Z. C. Li, J. W. Yuan, Y. M. Xiao, L. R. Yang, P. Mao and L. B. Qu, Chem. Commun., 2012, 48, 10117; (b) Q. Zhao, T. Miao, X. Zhang, W. Zhou and L. Wang, Org. Biomol. Chem., 2013, 11, 1867.

14 (a) J. Xiao, Q. Li, T. Chen and L. B. Han, Tetrahedron Lett., 2015, 43, 5937; (b) L. Zhang, P. Lu and Y. Wang, Org. Biomol. Chem., 2015, 30, 8322; (c) J. Kim, H. Kim and S. Chang, Org. Lett., 2012, 14, 3924; (d) S. Ding and N. Jiao, J. Am. Chem. Soc., 2011, 133, 12374.

15 (a) O. Grossman and D. Gelman, Org. Lett., 2006, 8, 1189; (b) Y. Z. Zhu and C. Cai, Synth. Commun., 2008, 38, 2753; (c) Y. Ren, Z. Liu, S. He, S. Zhao, J. Wang, R. Niu and W. Yin, Org. Process Res. Dev., 2009, 13, 764; (d) G. Yan, C. Kuang, Y. Zhang and J. Wang, Org. Lett., 2010, 12, 1052.

16 R. Aeluri, M. Alla, S. Polepalli and N. Jain, Eur. J. Med. Chem., 2015, 100, 18.

17 (a) S. Eagon, N. Ball-Jones, D. Haddenham, J. Saavedra, C. DeLieto, M. Buckman and B. Singaram, Tetrahedron Lett., 2010, 51, 6418; (b) S. Kamila, D. Zhu, E. R. Biehl and L. Hua, Org. Lett., 2006, 8, 4429.

18 (a) Q. Wu, Y. Luo, A. Lei and J. You, J. Am. Chem. Soc., 2016, 138, 2885; (b) S. E. Allen, R. R. Walvoord, R. Padilla-Salinas and M. C. Kozlowski, Chem. Rev., 2013, 113, 6234; (c) G. G. Melikyan, Org. React., 1997, 49, 427.

19 (a) Y. Yamamoto, M. Ohno and S. Eguchi, J. Org. Chem., 1996, 61, 9264; (b) R. S. Liu, S. M. Ghorpade and P. D. Jadhav, Chem.-Eur. J., 2016, 22, 2915; (c) C. Chatgilialoglu, D. Crich, M. Komatsu and I. Ryu, Chem. Rev., 1999, 8, 1991; (d) H. Ishibashi, M. Higuchi, M. Ohba and M. Ikeda, Tetrahedron Lett., 1998, 39, 75.

20 (a) G. Qin, X. Chen, L. Yang and H. Huang, ACS Catal., 2015, 5, 2882; (b) T. Nishikata, Y. Noda, R. Fujimoto and T. Sakashita, J. Am. Chem. Soc., 2013, 135, 16372. 